Foundation. Mr. Crary, a noted polar geophysicist, recently returned from two and a half years in Antarctica, where he was station scientific leader of the Little America Station and deputy chief scientist of the Antarctic programme of the U.S. National Committee for the International Geophysical Year. The United States Antarctic research programme has been established to co-ordinate the scientific efforts of Federal agencies with an interest in Antarctic research and to receive proposals by university scientists and independent investigators for polar research. The Foundation looks to the Committee on Polar Research of the National Academy of Sciences-National Research Council for recommendations regarding the desirability of proposed programmes. Mr. Crary will advise the Foundation in the planning of the scientific projects, selecting personnel and equipment, and will supervise the conduct of field investigations, data analysis, and publication. Mr. Thomas $\mathrm{O}$. Jones is director of the Antarctic research programme of the National Science Foundation. Mr. Crary will maintain offices at the Foundation and at Cambridge, Mass., where he will continue his affiliation with the Geophysics Research Directorate, Air Force Cambridge Research Center.

Geography at Sheffield:

Prof. C. A. Fisher

Mr. Charles Alfred Fisher, at present reader in geography in the University of Leicester, has been appointed to the chair of geography in the University of Sheffield in succession to Prof. D. L. Linton (see Nature, 182, 497; 1958). Mr. Fisher, who will take up his appointment in October, graduated at Cambridge with first-class honours in both parts of the Geographical Tripos. $\mathrm{H}_{\theta}$ was awarded a University Bartle Frere Research Exhibition in 1938 and for the next two years he undertook research at Cambridge. After nearly six years in the Army, Mr. Fisher took up an appointment in January 1946 as an assistant lecturer in geography at University College, Leicester, and later that year was appointed to a lectureship in geography at the University College of Wales, Aberystwyth, which he held until December 1949. Before returning to Leicester as a lecturer in 1951, Mr. Fisher held an appointment as senior research officer at the Institute of Colonial Studies, Oxford. In October 1958 the title of reader in geography in the University of Leicester was conferred on him.

In $1947 \mathrm{Mr}$. Fisher was awarded a Travelling Fellowship of the Royal Geographical Society which enabled him to make a series of study visits to Dutch universities and the Tropical Institute of Amsterdam in connexion with his researches on South-east Asia, and during the session 1953-54 he was a visiting lecturer in geography at Yale University, and was appointed Visiting Fellow of Trumbull College, Yale. Mr. Fisher has contributed chapters to several books and has published many articles on a wide range of geographical subjects, particularly on South-east Asia and the Far East.

Nuclear Technology at the Imperial College of Science and Technology, London

Courses of instruction and postgraduate research in the various branches of nuclear science and engineering given at the Imperial College of Science and Technology, London, include those on the theoretical and practical aspects of nuclear and highenergy physies (Physics and Mathematics Depart- ments); a postgraduate course in nuclear power (Department of Mechanical Engineering); and a new course in nuclear technology (chemical) (Chemical Engineering Department). This one-year course, which commences in the session 1959-60, is under the supervision of $\mathrm{Mr}$. G. R. Hall, reader in nuclear technology, assisted by Dr. H. D. Evans, Mr. S. Hartland and Dr. A. J. Swallow. In addition to topies relating to nuclear power production, such as fuel-element technology and the processing of irradiated fuels, a substantial part of the course will be devoted to the applications of radioisotopes as tracers and for non-destructive testing, and the possible uses of sources of radiation for inducing industrial-scale chemical reactions. Applications for admission should be made before June 1 , on a form obtainable from the Registrar, Imperial College of Science and Technology, London, S.W.7.

\section{Nuclear Training in the Biological Sciences in the United States}

The United States Atomic Energy Commission has approved thirty-two new grants totalling 316,717 dollars to thirty-one American colleges and universities. These grants are part of a programme to assist colleges and universities to expand their facilities for training in radiation biology and in the use of radioisotopes in the fields of agriculture, veterinary medicine, medicine and pharmacy, public health and biology. The new grants bring to $1,810,707$ dollars the total amount awarded in making 152 grants to 110 institutions since the Commission's programme was initiated in October 1957.

\section{The Australian National University : Field Station for Astronomy}

About a year ago the Department of Astronomy (Mount Stromlo Observatory of the Australian National University) initiated a survey to locate a suitable site for a field station. Excessive night cloudiness in Canberra and vicinity renders it impracticable to carry out at Mount Stromlo sustained long-range observational programmes. The intention is not to transfer major equipment from Mount Stromlo to the field station, but the University may want to place some future new equipment there rather than at Mount Stromlo. There is no question of transferring any of the research, teaching or administrative activities to the site of the field station. During the past year, tests for night cloudiness have been carried out at four localities, all of which are hill tops rising 700-1,000 ft. above the level of the surrounding plain, three in New South Wales and one in Victoria. According to the records gathered to date, Natimuk (Victoria) has the largest percentage of clear nights (65 per cent over 122 nights), Griffith has 54 per cent over 266 nights, Condobolin 47 per cent over 263 nights. Mount Stromlo had only 28 per cent clear over the $\operatorname{sam} \theta$ interval. Alectown and Lake Cargellico both show 40 per cent clear. All observations refer to the first half of the night.

Astronomical tests are to be initiated at various sites, notably near Natimuk, Griffith and Condobolin. Provided arrangements can be made for temporary occupation of the site, access roads, electricity supply and telephone service, a control station will be set up near Griffith and one of the smaller telescopes from Mount Stromlo Observatory will be moved there, with the intention of operating it for a period of eighteen months. Mobile telescopic equipment 